\title{
XII
}

\section{PANDE-MÍDIA: O DESAFIO DE ENFRENTAR A VIRULÊNCIA CONTRA O DES(RE)MONTE DOS SERVIÇOS PÚBLICOS*}

Lucia Cristina Dos Santos Rosa

Thaís de Andrade Alves Guimarães

\section{Introdução}

Apesar dos alertas dos riscos de epidemias viróticas que afetariam todo o planeta, emitidos pela Organização Mundial da Saúde OMS, órgão encarregado de coordenar e recomendar diretrizes de ações internacionais em saúde, a partir do ano 2000, na perspectiva de que os governos organizassem seus sistemas de saúde para controlar surtos, ficou evidente a dificuldade em planejar ações preventivas em sociedades capitalistas, que priorizam a economia, haja vista que o comunicado da pandemia da COVID-19 (ou vírus Sars-CoV-2), seguido de declaração de estado de emergência internacional de saúde pública, em 30 de janeiro de 2020, tomou de surpresa, parte expressiva dos governantes de vários países, levando alguns a banalizar a gravidade da situação.

Como esclarece a RADIS (FIOCRUZ, 2020) "é a sexta vez que a OMS decreta emergência de saúde pública internacional" (p. 16), sendo a primeira em 2009, em função da pandemia decorrente do Vírus H1N1; em 2014 a de poliomielite; em 2016 a de ebola, depois vírus da zika, que pode gerar malformações fetais congênitas (microcefalia) e em 2019 surto de ebola.

A pandemia afetou de maneira complexa e plural a vida dos países, com impactos graves na economia e na vida de todo ser humano, sobretudo no mundo Ocidental, em que a liberdade é um valor estruturante da sociedade, tendo que ser suspensa pelas medidas de distanciamento físico, subjacente à chamada "Fique em Casa".

*DOI- 10.29388/978-65-86678-44-4-0-f.309-336 
Logo, a sociedade capitalista que vinha em intensas transformações em seu mundo do trabalho, recriando suas formas domésticas, passando a se alimentar da nova junção entre espaço privado que também se expande ao espaço público, pelo trabalho remoto/home office.

O Brasil se insere nesse cenário, em um momento de grave crise econômica, com intensificação nas desigualdades sociais; política, com polarização da sociedade, avanço das forças conservadoras e crescente redirecionamento dos preceitos da Constituição de 1988, considerada marco da consolidação democrática no País, com desmonte da Seguridade Social, reforma previdenciária, alterações substantivas do Sistema Único de Assistência Social - SUAS e Sistema Único de Saúde - SUS, alterações no financiamento da Atenção Primária à Saúde, agravado pelo lançamento do Programa Previne Brasil, extinção do Núcleo Ampliado de Saúde da Família, extensivamente, com intensas mudanças na Rede de Atenção Psicossocial, na direção da sua remanicomialização (GUIMARÃES; ROSA, 2019).

Nesse contexto, os meios de comunicação, sobretudo as mídias virtuais, principalmente a Internet, a televisão e o rádio, que estão "imbricados com outras esferas da vida social" (SORJ; MARTUCCELLI, 2008) tornam-se uma das principais fontes difusoras e propagadoras de informações, que permite o acesso a conhecimentos estratégicos para qualificar, usufruir da cidadania e adensar a participação social ou desqualificá-la, haja vista a intensificação das fake news, que reforçam incertezas, contrainformação que tem bombardeado o cenário atual. Através do meio de comunicação a disputa ideológica se acirra, através de informações que podem qualificar a atuação política ou desvirtuá-la, mas, de qualquer forma, sendo fundamental para formar a opinião pública.

Como analisa Henriques (2020), apesar do País, ter um sistema de vigilância epidemiológico bem estruturado nos últimos 20 anos, o vírus chikungunya, a epidemia de dengue e vírus zika já assolavam o solo nacional. A COVID-19 levou o Brasil a decretar emergência em saúde pública, em 04 de fevereiro, estabelecendo-se o SUS como linha de frente para responder aos desafios postos. Entretanto, a falta de alinhamento nas orientações, sobretudo expressa por representantes da comunidade política em minimizar e até negar a gra- 
vidade imposta pela COVID-19, sobretudo ao desconsiderar as recomendações de distanciamento físico e as evidências científicas ao recomendar o uso da cloroquina e ter atitudes que confrontava as orientações do Ministério da Saúde, acompanhado pelo crescimento das fake news, notícias falsas veiculadas pelo Whatsapp envolvendo inclusive órgãos estratégicos da ciência, como a Fundação Instituto Oswaldo Cruz (FIOCRUZ), levou os órgãos a emitir recomendações aos demais níveis governamentais, sem tornar obrigatória as medidas elencadas, o que criou hiato entre os gestores das diferentes esferas, que tomaram providências específicas a partir da avaliação de seus contextos, acompanhado de tensionamentos entre o presidente da República e o ministro da Saúde - Luiz Henrique Mandetta, que foi demitido, sendo substituído por Nelson Teich, que ficou pouco tempo na pasta, entregue posteriormente a um militar, General Eduardo Pazuello, ou seja, as ações se tornaram efetivamente uma questão de comando de guerra, o que fez juz à linguagem adotada desde o início, como de enfrentamento e combate, que se naturalizou. Desconfianças e incertezas em termos de recomendações passam a cercar igualmente as orientações de representantes da OMS, cuja credibilidade fica exposta.

Como analisa Henriques (2020) o descrédito nas instituições tem

[...] elevado grau de desorientação e perda de referências por parte da sociedade, colocando-a em situação de risco. Integra-se, dessa forma, ao contexto de pós-verdade em que a crise de confiança nas instituições é sua maior expressão e em que as chamadas fake news vicejam e lhe dão concretude (HENRIQUES, 2020, p. 36-37).

A desconfiança institucional, é alimentada inclusive, pelo que agentes da comunicação social tem nominado como "infodemia", isto é, "excesso de informação sobre um tema" (HENRIQUES, 2020) que redunda na difusão e absorção da mesma de maneira a crítica, sem questionamento e checagem das fontes e dos conteúdos.

As disputas políticas em torno da verdade e as dificuldades em veicular informações qualificadas mediatizam todas as relações, inclusive entre profissionais de Serviço Social e a população usuárias dos serviços, o que requer da profissão analise mais acurada para re- 
alizar contextual, da conjuntura, decifrar a realidade, para manter a qualidade dos serviços prestados, como está previsto no Código de Ética da categoria (CRESS-RJ, 2005).

Este texto objetiva realizar um balanço, a partir da leitura do Serviço Social, das ações da Rede de Atenção Psicossocial/SUS e da Proteção Social Especial/SUAS na gestão municipal teresinense e sua interseç̧ão com a sociedade civil no enfrentamento da COVID-19. Para tanto, partiu-se do exame das matérias disponíveis na mídia virtual, no período de março a julho de 2020, período em que foi decretado o estado de urgência/calamidade no Brasil e em Teresina, em que foram intensificadas as medidas de "enfrentamento" à COVID19.

Partiu-se da seleção das notícias veiculadas pela Internet, tendo por foco as respostas ao contexto imposto pela COVID-19 a partir do SUS e do SUAS, na realidade teresinense. Tendo por palavras-chave: pandemia; COVID-19; quarentena, saúde; assistência social; e população em situação de rua, foram levantados os sites virtuais de emissoras de televisão e jornais, os endereços institucionais da Prefeitura Municipal de Teresina, da Fundação Municipal de Saúde e da Secretaria Municipal de Cidadania, Assistência Social e Políticas Integradas - SEMCASPI - e Defensoria Pública. No total, 34 notícias serviram de base para a análise, tendo por fonte 11 sites distintos, ganhando primazia os institucionais, dos serviços públicos.

$\mathrm{O}$ assunto que ganhou maior destaque, com uma representação de $42 \%$, foi sobre os serviços disponibilizados para o atendimento em saúde mental, à população em geral e para os servidores municipais e providências em torno das estratégias e respostas à COVID19. Em segundo lugar, evidenciou-se a situação das pessoas em situação de rua e as respostas do SUAS e do SUS em relação a esse segmento, representado em $34,3 \%$, havendo maior concentração na veiculação de informação nos meses de março e maio. A análise temática, que tem por base descobrir os núcleos de sentidos nas comunicações foi priorizada (BARDIN, 1988). 


\section{Respostas da gestão teresinense à situação de excepcio- nalidade da COVID-19: repercussões no SUS e SUAS}

Teresina, capital do Piauí, situada na região Nordeste, com uma população de 814.230 habitantes (IBGE, 2010), cuja economia gira em torno do setor de serviços e comércio, principalmente, estruturou sua Rede de Atenção Psicossocial - RAPS tardiamente, tendo por principais atores impulsionadores do processo de construção local da reforma psiquiátrica a: Coordenação de Saúde Mental, do Ministério da Saúde, com suas políticas indutoras, sobretudo a partir da Portaria no 1.455/2003, a gerência estadual de Saúde Mental, da Secretaria de Estado da Saúde - SESAPI e o Ministério Público Estadual (SEABRA; ROSA, 2018). A Associação Psiquiátrica do Piauí, se configurou no processo com a bandeira contrarreformista. A Âncora, Associação de usuários, familiares e pessoas interessadas na causa da saúde mental, atuou apoiando os processos antimanicomiais.

A construção da RAPS teresinense ganhou impulsionamento intenso a partir de 2010, com o fechamento do Sanatório Meduna, um manicômio privado, conveniado ao SUS, com 200 leitos, o que reverberou na aceleração da criação de serviços como Centros de Atenção Psicossocial e outros equipamentos comprometidos com o cuidar em liberdade, no território, onde a vida acontece.

O Ministério Público Estadual teve um papel determinante, através de estratégias como audiências públicas mas, principalmente pela força impositiva dos Termos de Ajustamento de Conduta e ação conjunta com a gerência estadual e municipal da capital, para realizar uma avaliação situacional e de diagnóstico da realidade das pessoas internadas em hospitais psiquiátricos em 2009/2010, o que redundou na construção do desenho da RAPS da capital, assim configurada em 2018: 
Quadro 1: Serviços da rede de atenção psicossocial implantados em Teresina

\begin{tabular}{|c|c|c|}
\hline CATEGORIA & TIPO DE SERVIÇO & QUANTIDADE \\
\hline \multirow{3}{*}{ Atenção Básica em Saúde } & Unidade Básica de Saúde & 90 \\
\hline & $\begin{array}{l}\text { Núcleo de Apoio à Saúde da } \\
\text { Família }\end{array}$ & $\begin{array}{l}\text { 3, nas zonas sul, norte } \\
\text { e leste, com } 3 \\
\text { psicólogos. }\end{array}$ \\
\hline & Consultório na Rua & 1 \\
\hline \multirow{4}{*}{ Atenção Psicossocial } & CAPS ad Tipo II & 1 \\
\hline & CAPS Tipo II & 4 \\
\hline & CAPS Tipo III & 1 \\
\hline & CAPS i & $\begin{array}{l}\text { 2, sendo um de gestão } \\
\text { estadual e outro } \\
\text { municipal. }\end{array}$ \\
\hline \multirow{2}{*}{$\begin{array}{l}\text { Atenção de Urgência e } \\
\text { Emergência }\end{array}$} & SAMU 192 & 1 \\
\hline & UPA 24 Horas & 3 \\
\hline \multicolumn{3}{|l|}{$\begin{array}{l}\text { Atenção Residencial de } \\
\text { caráter transitório }\end{array}$} \\
\hline Atenção Hospitalar & $\begin{array}{l}\text { Enfermaria especializada em } \\
\text { Hospital Geral }\end{array}$ & $\begin{array}{l}10 \text { leitos, no Hospital } \\
\text { do Mocambinho. }\end{array}$ \\
\hline \multirow[t]{2}{*}{$\begin{array}{l}\text { Estratégias de } \\
\text { Desinstitucionalização }\end{array}$} & $\begin{array}{l}\text { Serviço Residencial Terapêutico } \\
\text { Tipo I }\end{array}$ & 3, de gestão estadual. \\
\hline & $\begin{array}{l}\text { Serviço Residencial Terapêutico } \\
\text { Tipo II }\end{array}$ & 1, de gestão municipal. \\
\hline
\end{tabular}

Fonte: Gerência de Atenção Psicossocial de Teresina, 2018.

Logo, Teresina, conta com, pelo menos, um Centro de Atenção Psicossocial em cada zona/região da cidade, mas, para a atenção à crise conta apenas com um Caps tipo III, que funciona com pernoite, com 8 leitos, reduzido para 4 no contexto da COVID-19, tendo no Hospital Areolino de Abreu, sob gestão estadual, com 160 leitos, a principal porta de entrada para atenção de urgência e emergência psiquiátrica.

O Sistema Único de Assistência Social, destinado ao público que dela necessitar, ou seja, as pessoas consideradas em situação de vulnerabilidade e risco social, assim como o SUS/RAPS, está estruturado segundo a lógica territorial, tendo igualmente, pelo menos um equipamento em cada uma das 4 zonas da cidade: Território Norte, Território Sul, Território Leste e Território Sudeste. Nestes territórios encontram-se distribuídos serviços de proteção social básica, média e alta complexidade, de implementação direta do gestor municipal ou 
por entidades sem fins lucrativos - organizações não governamentais - ONG, no geral conveniadas com a Secretaria Municipal de Cidadania, Assistência Social e Políticas Integradas - SEMCASPI.

A Proteção Social Básica, com foco de atuação na ação preventiva, protetiva e proativa, visa fortalecer os vínculos familiares. Conforme dados do CNEAS 2017, em Teresina, a proteção social básica dispõe de uma gerência que coordena a gestão de 19 Centros de Referência da Assistência Social - CRAS, que devem referenciar até 5.000 famílias cada um, por meio do Serviço de Atenção Integral à Família - PAIF. Contam também, com 71 Serviços de Convivência e Fortalecimento de Vínculos - SCFV, destes, 14 é de execução direta do órgão gestor e 37, a maioria, executados por entidades socioassistenciais da Sociedade Civil Organizada (PREFEITURA MUNICIPAL DE TERESINA, 2018).

A Proteção Social de Média Complexidade destinada às famílias e indivíduos em situação de risco pessoal ou social, cujos direitos tenham sido violados ou ameaçados, tem seus serviços articulados com o sistema de garantia de direitos, com ação compartilhada com o Poder Judiciário, o Ministério Público, Delegacias Especializadas e outros órgãos e ações do Executivo. É composta por: 04 Centros de Referência Especializados da Assistência Social- CREAS, 01 Centro de Referência Especializado para População em Situação de Rua - CENTRO POP, 02 Centros Especializados para Pessoas com Deficiência CENTROS DIA, serviços estes de proteção social especial de média complexidade de gestão direta da SEMCASPI. (PREFEITURA MUNICIPAL DE TERESINA, 2018).

No âmbito da implementação da Proteção Social Especial de Alta Complexidade predomina a representatividade das entidades socioassistenciais sem fins lucrativos (ONG) na dinamização de serviços de acolhimento institucional. A rede municipal dispõe de 05 unidades de acolhimento institucional para crianças, sendo 01 sob gestão municipal, 01 sob gestor estadual e 03 executados por ONG. Na modalidade de Acolhimento Familiar, Teresina apresenta 02 serviços, sendo 01 deles de execução municipal. $O$ acolhimento institucional para adolescente conta com 03 unidades; 02 do Estado e 01 do município. Para o acolhimento da Pessoa idosa a rede de proteção social do município dispõe de 05 unidades: 01 municipal, 01 estadual e 03 
sob administração de entidades socioassistenciais privadas. Para o acolhimento da população em situação de rua o município dispõe de um albergue, para pernoite, denominado Casa do Caminho. Parte significativa das ações com a população em situação de rua é endereçada para instituições não governamentais, sobretudo as comunidades terapêuticas e Pastoral de Rua.

Com a Constituição de 1988 ratificando muitas conquistas inerentes às lutas sociais da sociedade brasileira, sobretudo alterando as características da lógica e implementação das políticas sociais, na direção de uma atenção descentralizada, mais próxima do território e contexto de vida (residência e circulação) do cidadão; voltada para a integralidade; participação social, torna-se imperativo a intersetorialidade entre as diferentes políticas, na direção de maior horizontalidade de ações, trocas de saberes, experiências e ação interdisciplinar, superando as formas fragmentadas por necessidades, públicos e ações pontuais.

O Sistema Único de Saúde - SUS e o Sistema Único de Assistência Social - SUAS atuam com os mesmos segmentos populacionais e encontram-se igualmente nos mesmos territórios, considerados "vulneráveis", o que, em tese, facilita a sinergia de ações conjuntas e tem sido fomentado por vários textos ministeriais, sobretudo após 2010, quando é lançado o Decreto no 7.179, o Plano Integrado de Enfrentamento ao Crack e Outras Drogas, posteriormente, transformado no Programa Crack, é possível vencer, materializado em ações como financiamento para criação do Comitê Local de Gestão do Plano Integrado de enfrentamento ao Crack, gerido, pela denominada, em 2016, Secretaria Municipal de Assistência Social, SEMTCAS, metamorfoseada em SEMCASPI, que, pelo final da denominação contempla a perspectiva de políticas integradas, mas, na prática, integrou a assistência social com a segurança pública, o que recompõe no espaço local o binômio assistência repressão que cercou a gênese da política social de assistência social no País.

Outro exemplo, na direção do fomento à intersetorialidade é o Caderno de Orientações técnicas: Atendimento no SUAS às famílias e aos indivíduos em situação de vulnerabilidade e risco pessoal e social por violação de direitos associada ao consumo de álcool e outras drogas (BRASIL, 2016) que mostra a convergência, interfaces e objeti- 
vos da política de assistência social e saúde, embora, no plano local se observe alguma dificuldade de ações conjuntas, mesmo intrasetorial, persistindo ainda características das marcas históricas de serviços e políticas atuando isoladamente, com parca comunicação e articulações entre si, as quais, mesmo quando ocorrem é pela via da intervenção dos profissionais e não dos e entre gestores, como seria o desejável, mesmo que o público-alvo e o nível de gestão seja o mesmo, figurando cada secretaria/pasta como uma miniprefeitura, sem imbricação com a realidade da cidade e as necessidades socioassistenciais e sanitárias de cada território

As respostas à situação de emergência internacional e nacional imposta pelo risco de disseminação da COVID-19 reverberou desigualmente entre os diferentes segmentos sociais, assim como entre gestores dos diferentes níveis governamentais do País, pois não houve padronização de orientações, condutas ou protocolos. Muito embora o Ministério da Saúde tenha adotado as recomendações da Organização Mundial da Saúde, não houve alinhamento intragovernamental sobre as coordenadas gerais, havendo hiato a partir da conduta do presidente da República, que contrariava as evidências científicas. A reação inicial de perplexidade, surpresa, certa inercia e desencontro de direções, teve que ser alterada, pois, os impactos econômicos, sociais, políticos, culturais, familiares e pessoais das medidas de distanciamento físico exigiram intensas mudanças na vida como um todo, na cidade, no trabalho, na sociabilidade, alterada pelas medidas de distanciamento físico, afetando processos de trabaIho, sendo requisitado o trabalho remoto, realizado em casa, havendo junção entre esfera pública e privada.

Em Teresina, pelo Decreto no 5.499, de 09 de março de 2020 o prefeito dispõe sobre as medidas de enfrentamento da emergência em saúde pública decorrente do coronavirus" e pelo Decreto no 19.537, de 20/03/2020 decreta "estado de calamidade pública" e em seguida, em conjunto com o governador, assina decreto instituindo "lockdown parcial", como medida para conter o risco de expansão de casos de COVID-19 abrangendo limitações no funcionamento de atividades, sobretudos econômicos nos finais de semana, a partir de 26/06 previsto vigorar até final do mês de agosto, o que corroborado pelas falas do Prefeito na imprensa televisiva, sinalizam para suas 
preocupações apoiadas em análises e recomendações científicas sobre as melhores práticas para conter a propagação do vírus, parecendo convergir o comportamento político da autoridade máxima da capital local, com as orientações e evidências científicas. Segundo afirma o prefeito, em reportagem televisiva da Cidade Verde, de 27 de março de 2020 é "importante que se leve a sério o que os especialistas dizem". Em 29 de março de 2020, pelo GP1 confirma por redes sociais duas mortes pela COVID-19 na capital, um casal, ambos envolvendo pessoas com mais de 70 anos, considerados do grupo de risco, cuja infecção foi caracterizada como comunitária, transmitida por um filho, que teve aproximação com alguém contaminado (MARTINS, 2020).

Em Teresina, na mídia virtual, no início da implementação das medidas de distanciamento físico (ABRASCO, 2020) o assunto que se sobressaiu inicialmente, com uma representação de $42 \%$, esteve relacionado aos serviços disponibilizados para o atendimento em saúde e saúde mental, à população em geral e para os servidores municipais e providências em torno das estratégias e respostas à COVID19. Como no restante do país, o hospital geral, a alta complexidade foi enfatizada midiaticamente, quer pela construção ou improvisação de hospitais de campanha e compras de respiradores, o que associava a COVID-19 à urgência e ao risco de morte iminente, secundarizandose as orientações da OMS que $80 \%$ dos casos eram leves e que poderiam ser tratados em casa, com retaguarda da Atenção Básica/Primária.

Mas, além do lugar privilegiado dado à alta complexidade, é noticiado a associação entre a Prefeitura Municipal de Teresina e o Governo do Estado, na criação de um Centro de Acolhimento e Isolamento Social - CAIS, privilegiando a gestão pelo Terceiro Setor. Vale lembrar que Teresina ainda tem umas RAPS predominantemente pública, mas, a participação das organizações governamentais, sobretudo na modalidade das comunidades terapêuticas, tem crescido, não somente no número de serviços e no carreamento de recursos públicos, mas, na disponibilização de equipamentos públicos, cedidos para serem geridos por esses entes, com intensa transferência da responsabilidade público estatal, para esses entes. 
Em 20 de maio de 2020, no site da Fazenda da Paz e em 22 de julho de 2020, no site do Governo do Piauí, é noticiado que "Fazenda da Paz gerenciará abrigos de isolamento para pessoas com COVID19", o Centro de Acolhimento e Isolamento Social - CAIS e do Governo do Piauí "Teresina ganha o centro de acolhimento para casos leves de COVID-19" (COSTA, 2020). Destinados para aquelas pessoas que "apresentem sintomas leves ou são assintomáticos, e que não tem condições de realizar o isolamento social de 14 dias em casa. São 200 vagas, distribuídas em 4 abrigos, cada um em uma das zonas da cidade, ocupando o primeiro, uma escola pública, Unidade Escolar Gabriel Ferreira. O CAIS parte da captura de recursos, por iniciativa da vice governadora, Regina Sousa, do projeto Todos pela saúde, lançado pelo Itaú Unibanco, em articulando Fazenda da Paz, Secretaria de Estado da Educação - SEDUC e Fundação Municipal de Saúde de Teresina. Uma organização não governamental, gerenciara o abrigo, delegado para o terceiro setor, cujo conteúdo da matéria, sinaliza que 'é preciso se preocupar com os mais pobres. E é preciso um serviço para combater a propagação do coronavirus'". Assim, como afirma Ana Elizabete Mota (1995), a crise não repercute igualmente para todos, alguns segmentos inclusive lucram com a mesma. Com certeza, há muitas pessoas que são infectadas e que não conseguiriam se isolar em casa, por um período de 14 dias, dadas as próprias condições de vida e, sobretudo habitação. Mas, em momento algum é chamada a participação de conselheiros de saúde e assistência social para tal decisão, assim como não se parte de um diagnóstico embasado. Uma questão, o recurso financeiro investido nesse CAIS, se fosse transferido para cada família exposta às condições estabelecidas, para que construísse um quarto, não permitiria mudança mais efetiva, não apenas na pessoa infectada, mas, na vida da família como um todo? Tal medida, não ficaria menos onerosa aos cofres públicos e não teria maior impacto social? Infelizmente, não se observou questionamentos sobre as decisões tomadas.

Os redirecionamentos dos processos de trabalho dos serviços também ganharam destaque, através da criação de um grupo denominado "força tarefa, pela Fundação Municipal de Saúde (PREFEITURA DE TERESINA, 2020). 
Em saúde mental, na RAPS, para atender a excepcionalidade do momento, 3 alternativas foram publicizadas para atendimento ao público em geral: os Centros de Atenção Psicossocial - CAPS; o PROVIDA, via teleatendimento e a urgência, 193 ou Hospital Areolino de Abreu. Com serviços ambulatoriais de saúde mental fechados, os 7 CAPS do município, que foram sobrecarregados com a busca de atendimento para agravos considerados leves para a saúde mental e por demanda de familiares de pessoas com transtornos mentais, figuraram para as situações de transtornos mentais severos e persistentes, como prevê a Portaria GM/MS no 336/2002; o Provida voltado para atender pessoas com ideação suicida (também via teleatendimento acesso via Alô Saúde Teresina) e a urgência, para situação de agravos, crise psiquiátrica. As atividades coletivas foram suspensas, em nome de evitar aglomerações, sem se cogitar a possibilidade de ações virtuais, houve redução no número de leitos no único CAPS III da capital e do Estado, de 8 para 4, sob a mesma alegação, igualmente, as equipes foram reduzidas. Ao se reconhecido os riscos para os trabalhadores de saúde/saúde mental, também foi investido na abertura de serviços via telefônico para atendimento aos servidores públicos, mediante prévio agendamento.

Em segundo lugar, na mídia virtual, tanto na mídia escrita/virtual, quanto televisiva, representando $34,3 \%$ entre os assuntos veiculados, se sobressaiu aqueles atinentes à resposta do poder público à realidade da população em situação de rua - PSR, no cenário pandêmico.

O que catalisou as manchetes foi o fechamento em 22 de março de 2020, do Albergue Casa do Caminho, único equipamento público, sob coordenação da SEMCASPI, órgão gestor local da política de assistência social, destinado ao abrigamento, para pernoite, da população em situação de rua, estimada em 300 pessoas pela pesquisa nacional de 2009 e em 400 pelo IBGE em 2008, segundo reportagem da TV Clube de 2013. No contexto da "quarentena" o jornal Cidade Verde, estima em aproximadamente 40 pessoas em situação de rua que necessitaria de abrigamento, que ficou desassistida, à mercê da rua, sem transeuntes que permitiam "um trocado", o que antes viabilizava a sobrevivência do dia e outras trocas, e agora, sem proteção social mínima, que deve ser oferecida e garantida pela política de 
assistência social, portanto, mais exposta à contaminação e outros agravos à saúde, pois sem acesso a espaço de proteção, à alimentação, água (segurança alimentar de modo geral), demais condições de higienização e equipamentos de proteção individual (CARPASO, 2020).

Em reportagem televisa que foi ao ar, dia 27/03, intitulada "Firmino sobre liberar isolamento: "Quem vai se responsabilizar pelas mortes? ", dentre muitos assuntos e frentes de resposta às medidas da COVID-19, pede desculpas aos "moradores de rua" "sobre a falta de assistência nos primeiros dias de isolamento. Não houve uma avaliação correta com relação aos moradores de rua". Como visto, a questão parece ser remetida apenas aos gestores e especialistas, pois não houve uma análise da exclusão/falta de participação dos próprios interessados na construção de respostas à situação de rua, no contexto da pandemia. Prevalece ainda uma visão hierárquica e centralizada da resolução dos problemas candentes da cidade e de seus distintos segmentos, na figura dos tomadores de decisão, os gestores, o que se traduz na ação e tradição autoritária que presidiu o País e perdura, mesmo na fase considerada de consolidação democrática.

Nesse contexto, em que, para a população que tem casa para se proteger, a sala (SENNETT, 1988) a tela e os olhos (quer seja centrado na televisão, celular, internet) se tornam o principal mediador, agora em tempo real, com o mundo externo, simbolizando o risco de intensificação do "declínio da vida pública" (parafraseando Richard Sennett, 1988) agora obstado pela impossibilidade de manifestação física (presencial) em praça pública, o que no contexto dado, tem sido recriado, com as manifestações on line. Todos passam a depender cada vez mais dos veículos de comunicação virtual e produção cultural, que processam e difundem as informações a serem consumidas, escolhendo o que é ou não noticiável, conforme sua perspectiva, que não é neutra, sendo, sobretudo na contemporaneidade, um dos principais meios de forjar a opinião pública e realizar a educação da população.

Como analisa Marx e Engels, (2001), as "ideias dominantes de uma época nunca passaram das ideias das classes dominantes" (2000, p.83), que se tornam hegemônicas, se espraiam para toda sociedade como se fossem ideias universais, que atendem os interesses 
de todos, tendo o propósito de dominar, o que ocorre não apenas no plano econômico, mas também no plano das ideias, com interferência na forma de sentir, desejar e pensar. Logo, os meios de comunicação e produção cultural, contribuem na formatação e propagação de uma visão de mundo, no geral, a dominante.

Em tempos de intensificação das disputas político-ideológicas por visões de mundo (GRAMSCl, 1978), mas particularmente a partir das disputas das últimas eleições presidenciais no Brasil, em que o uso e a produção de fake news tornou-se instrumento intensamente adotado, observa-se a incidência de ações voltadas para conformação da opinião pública contrária às conquistas democráticas, de claro teor conservador e antipovo/antifacista.

Mas, os meios de produção midiáticos, também são espaços contraditórios e se situam nas disputas político ideológicas em torno do direito à informação, base fundamental na conformação e do exercício da cidadania, que o Art. 5o da Constituição Federal Brasileira de 1988, situa no rol dos direitos humanos fundamentais (SARLET; MOLINARO, 2014), o que tem que ser assegurado por todos os serviços públicos e pela sociedade em geral, buscando retratar a pluralidade de necessidades, visões de mundo e opiniões, inclusive divergentes, de maneira a contribuir para que as pessoas tenham acesso à informação de qualidade, baseada em evidências científicas que permitam fazer escolhas a partir de conhecimento balizado.

Ao se analisar o episódio do fechamento do abrigo destinado para atender PSR (Casa do Caminho), que foi acompanhado pelo fechamento das atividades do Restaurante Popular, um serviço gerido por uma ONG, comunidade terapêutica, que também atendia essa população (com 70 refeições diárias) e o próprio Centro Pop, observa-se a diferença no trato da notícia, entre diferentes empresas jornalísticas. A cidadaverde.com, em matéria veiculada em 25 de março de 2020 e intitulada "Pessoa em situação de rua serão acolhidas em escola para quarentena" de forma aparentemente neutra, informa que o albergue "suspendeu esse serviço devido a pandemia do coronavirus" e prossegue sinalizando a busca de alternativas, empreendida pelo Padre João Paulo Carvalho, da Pastoral do Povo de Rua, que procura retaguarda na instância estadual de governo, que 
se propõe a resolver a questão cedendo uma escola pública para tanto (CARPASO, 2020).

Observa-se que as violações de direitos sociais, sobretudo ao abrigo e à segurança alimentar, sequer são mencionadas, despindose a notícia de qualquer dimensão crítica e relação com a política social, que circunscreve direitos no registro da cidadania. O contexto da pandemia parece "naturalmente" justificar violações de direitos por entes públicos, na concepção subjacente à notícia veiculada, como a "suspensão" das atividades de um abrigo e restaurante popular, que devem assegurar o atendimento de necessidades básicas (PEREIRA, 2000). A produção de alternativa, por um ente da sociedade civil, o padre e desresponsabilização da política de assistência social municipal da capital, é ignorada.

Mas, outros canais, embora com tendência à reprodução do mesmo padrão, tem um trato mais ampliado, possibilitando, por exemplo, vocalização direta da PSR, sem a intermediação de outros entes, sobretudo Organizações Não Governamentais, como no geral ocorre, em nome de uma perspectiva salvacionista, muito embora, alguns contextos de realização das matérias ocorram em momentos de "doação" de serviços por esses entes, a exemplo de distribuição de quentinhas, como é veiculado em 25 de março de 2020 pelo Portal Oito Meia, a PSR é nomeada na reportagem como "moradores de rua", "quem não tem como evitar aglomerações", "pessoas mais carentes", "desinformados", sendo retratados como historicamente o foram, pelo que não tem, por suas faltas, sobretudo materiais, econômicas (TEIXEIRA, 2020).

Um representante do grupo, ao relatar o que experienciaram denuncia, o que é confirmado pelo secretário da SEMCASPI, de que estavam abrigados e foram expulsos (da Casa do Caminho), desabrigados, comparando o que o segmento vivencia no Piauí, sobretudo em Teresina, com o que ocorre em outros Estados, em que os gestores têm buscado acolher esse segmento, mesmo que em ginásios, chácaras e centros de recuperação, lugares improvisados, mas, que denotam preocupação na continuidade da assistência desse grupo, no contexto pandêmico. Contrastando a visão do pobre e da pobreza veiculada midiaticamente, representantes da PSR aceitam se pronunciar publicamente, e mostram que detêm informações atualizadas, 
sobre o que ocorre em outros contextos. Comparam ainda a realidade em que vive com a vida do Prefeito, que tem uma casa para abrigá-lo e alimentação garantida, convocando o reconhecimento da cidadania, no princípio da justiça social. Avaliam que são tratados como "copos descartáveis", ou seja, lixo, algo incinerável (que pode ser ateado fogo) e apenas com medidas repressivas, posto que é informado que mesmo nesse contexto, um grupo de PSR estava dormindo ao redor de um serviço de saúde sob gestão municipal e foi ameaçado pela polícia, sendo tratados como "bandidos", o que sinaliza para a persistência da associação desse grupo à criminalidade, contrariando o Decreto federal $\mathrm{n}-7.053$, de 23 de dezembro de 2009, que institui a Política Nacional da População em situação de rua e confirma seu estatuto como cidadãos, sujeitos de direitos.

O secretário da assistência social argumenta que a medida de fechamento do serviço ocorreu para "evitar aglomeração", sem que participassem do processo e resolução acerca de seu destino, o que é previsto na política de assistência social, a partir da Constituição Federal de 1988. Fica subjacente nesse ato, a ideia de que o gestor faz por eles, e não com eles, desconsiderando os como sujeitos de direitos e cidadãos, capazes de propor, negociar, reinventar conjuntamente alternativas. Afinal, se vão tomar medidas que impactam suas vidas, nada mais cidadão do que construir com eles as possibilidades, pois sofrerão diretamente as repercussões das decisões. Ainda, a distribuição de alimentação (quentinha, como é retratado na reportagem) e equipamentos de proteção individual (EPI), quando ocorre, é informado que se dá em número insuficiente, como informam algumas PSR. A reportagem informa que havia 80 pessoas do local da reportagem, apenas 65 receberam a quentinha, ou seja, 1/4 ficou sem acesso, o que pode comprometer a sobrevivência.

Como resposta à violação de direitos, como publicizado, observa-se através de outras reportagens, que o sistema de garantia de direitos é colocado em cena, muito embora, de maneira pontual, impondo medidas por tempo determinado pela pandemia/quarentena.

No site da Defensoria Pública do Piauí (2020), de 26/03 é retratado como manchete "Defensoria consegue liminar com medidas de proteção para a população em situação de rua", na perspectiva de que seja cumprida "integradamente" ou seja, intersetorialmente, en- 
tre a política de assistência social e saúde, no contexto da pandemia, o que não deveria ser algo pontual, mas, parte do processo de construção e da ação em rede. No GP1 (2020), é anunciado em 26 de março de 2020 que "Juiz determina medida para atender População em Situação de Rua durante quarentena em Teresina". Logo, o que é um direito, volta a ser afirmado como circunscrito a uma temporalidade, excepcional, tendo que ser acionado como tal, no plano jurídico, não basta sua afirmação em uma política social e na Constituição Federal de 1988 , tem que ser reclamados judicialmente. Como bem discute Norberto Bobbio (2004), todos os direitos já estão inscritos na lei, mas, infelizmente, para serem usufruídos, tem que ser acionados.

Em matéria com o mesmo teor, veiculada pela Associação dos Magistrados Piauienses - AMAPI, no mesmo dia 26 de março de 2020, nomeada "Juiz fixa medidas para atendimento a moradores de rua em Teresina durante pandemia do coronavírus". É exposto que:

\begin{abstract}
A decisão determina que os órgãos devem distribuir alimentação às pessoas em situação de rua e àquelas pessoas que dependem da alimentação do Restaurante Popular, que foi fechado em virtude do decreto de calamidade pública; bem como água potável para consumo pessoal, em vários pontos da cidade de Teresina. "Em meu entendimento, até pode ser determinada a suspensão temporária dos serviços prestados por este restaurante, desde que alternativas sejam postas em prática para manter o mínimo de dignidade às pessoas que dele dependam. Apesar da grave epidemia, não me parece proporcional nem razoável impor, a qualquer custo, a interdição ou fechamento de certos estabelecimentos que garantem um meio de subsistência aos moradores de rua. Em minha concepção, a COVID-19, por mais grave que seja, não justifica o sacrifício de uma classe social desfavorecida de recursos financeiros", diz o magistrado na decisão". o juiz determina ainda que Estado e Prefeitura forneçam abrigos para acolhimento da população vulnerável em condição de abandono e situação de rua, em locais arejados, que tenham espaços suficientes para serem alojados sem aglomeração. O Centro Pop também deverá ser reaberto, todos os dias da semana, nos três períodos, para facilitar o acesso a banhos e outras formas de higiene (AMAPI, 2020).
\end{abstract}

Observa-se que o Juiz determina que alternativas sejam construídas, ou seja, a PSR não pode ficar desassistida. Embora invoque o princípio do "mínimo de dignidade", o magistrado, que no geral tem 
uma relação orgânica com as classes dominantes, refere-se à PSR como "classe social desfavorecida de recursos financeiros", ou seja, ratifica o imaginário dominante que a PSR é aquela destituída de bens materiais, financeiros, renda, ignorando que o que está em jogo é a destituição de um direito social, inerente à condição de cidadania. Assim, os recursos simbólicos e o poder da participação social, são ignorados. Como discute Sposati (1988) “[...] os usuários dos serviços assistenciais são qualificados como "necessitados e carentes" e não como cidadãos usuários" (p. 47), sendo o trato que os segmentos dominantes destinam ao pobre e a pobreza. Entretanto, nas lutas sociais e disputas ideo-políticas, representantes da própria PSR resiste a esse trato.

Desde 10 de abril de 2020, a PSR passa a ser abrigada no estádio municipal Lindolfo Monteiro, ou seja, alternativas foram construídas pela gestão pública de Teresina, mesmo que de maneira improvisada, com um estádio sendo transformado em alojamento, com capacidade de acolher 70 pessoas, abrigando então 20. Mas, a questão que parecia resolvida, encontrou resistência de parte da PSR. Em reportagem televisiva, TV Cidade Verde, afiliada do Sistema Brasileiro de Televisão (SBT), em 08 de maio de 2020, com a manchete "Moradores de rua em Teresina resistem em ir a abrigo montado em estádio" (SOUSA, 2020).

Primeiro há uma generalização, como se todos recusassem o abrigo. Segundo, sem recuperar o processo que culminou com a solução objeto da resistência, informa que a "Prefeitura disponibilizou" um local para o segmento, que "resistem em ir em abrigo montado em estádio". Duas pessoas do sexo masculino, que são majoritários entre esse segmento, se pronunciam na reportagem. Um deles sinaliza para os estigmas que acompanham o segmento, pois são "acusados de delitos" que não cometeram, são "marginalizados e excluídos" pela sociedade em geral. Ao se referir à resistência em ir pro abrigo, ou seja, politicamente aproveitam o espaço, para apresentar o imaginário social que os acompanha. Com relação à resistência ao abrigo, ambos argumentam que o estádio propicia aglomeração, o que não é recomendado para o contexto. Para um deles, o estádio-alojamento "é um campo de concentração moderno. Você imagina 70 a 100 homens, em estado de abstinência e jogar todo mundo num lugar só". É 
mostrada a contradição, pois em um momento que as recomendações requisitam evitar aglomeração, o alojamento reflete o contrário. Além de, ao impor restrição à entrada e saída, até como medida de contenção para o consumo de spa, levaria aqueles que consomem a uma circunstância de abstinência forçada. Embora contando com ações integradas entre a política de assistência social e saúde, o espaço não é um serviço de saúde.

Segundo título da reportagem do Portal Odia.com (20/06), escrita por Oliveira (2020), "Moradores de rua se recusam a ficar em abrigo de Teresina", recusa, mais uma vez, generalizada, o que não confere, e que é atribuída ao fato que de "não há possibilidade de usarem nenhum entorpecente. Por isso a recusa em se alojar". Tal visão, que configura uma violência, homogeniza um grupo plural, heterogêneo, como reconhece o texto da própria política, tornando todos, consumidores de substâncias psicoativas. Segundo os culpabilizam, como historicamente ocorre, por não "aceitar" o que é ofertado, do jeito que é ofertado.

Tal perspectiva é apreendida no trecho da reportagem que traz a situação de uma pessoa do sexo masculino, de 29 anos, que "é uma dessas pessoas em situação de rua que resistem em ir para o alojamento [...] local onde teria atendimento de saúde, refeições, cuidados higiênicos e orientações, sem falar que poderia participar de oficinas profissionalizantes que são oferecidas pela SEMCASPI". A reportagem não traz o conteúdo da fala da própria PSR. Fica subjacente, como mensagem subliminar do texto, que ao ter abrigo, alimentação, entretenimento, profissionalização, na ótica do gestor e do produtor da matéria, bastaria. Assim a PSR é reduzida à sua condição biológica, animal, tendo apenas que aceitar o que é ofertado, por dever de ofício, no caso, principalmente, de convocação/imperativo jurídico/judicial. Logo, para quem não aceita, só teria como outra "opção", permanecer na rua. Mais uma vez é violado o princípio da participação social e até o direito ao contraditório, como são garantidos constitucionalmente, o que também é obstado porque a PSR não é estimulada a se organizar politicamente, no plano local, como ocorre em outros contextos. Também não se observa nenhuma comissão de direitos humanos procurar ou ser procurada para se manifestar sobre a questão. 
Ainda na reportagem de 20 de junho de 2020, apenas a perspectiva da gestão se faz ouvir, sem que o direito ao contraditório seja assegurado, configurando uma reportagem tendenciosa, favorecedora da visão de mundo apenas dos grupos dominantes, estigmatizadora da PSR, na direção da "cruel compaixão" (SZASZ, 1994), no pressuposto de que ao assistido/recebedor somente restaria aceitação, resignação/conformismo, não resistência. Fica também evidenciado que na gestão do alojamento há o predomínio da leitura proibicionista sobre o consumo de spa, o que parece ratificar uma perspectiva segregadora, corroborado pelo contexto da pandemia, em que as liberdades em geral ficam cerceadas. Como é explicitado na reportagem “Então, como a maioria é usuária de alguma droga, eles saem. Mas quando voltam precisam passar por uma triagem com os profissionais de saúde que dão plantão no local. Pois se a pessoa apresentar qualquer sintoma, ela não fica lá". Ou seja, há uma perspectiva de restrição de liberdade, que se quebrada, já está no suposto da quebra para o consumo de spa. Não fica claro o que seria o detector ou critério para definir "sintoma", mas o profissional de saúde parece ser colocado no lugar de guardião, daquele que vai preservar as regras do local, agente do controle, da disciplina.

Os princípios que regem a política de redução de danos, que seria cidadã na abordagem desse segmento por se basear nos princípios dos direitos humanos e focar sobretudo nas pessoas que não querem, não podem ou não desejam deixar de consumir spa, parecem desconhecidas. Vale lembrar que parte significativa dessa população é não branca, negra, o que também sinaliza para violação dos princípios e da Política Nacional de Saúde Integral da População Negra, instituída pela portaria $\mathrm{n}$ - 992, de 13 de maio de 2009, que se orienta para a implementação do princípio da equidade.

Outras reportagens alusivas à PSR foram veiculadas virtualmente. No endereço eletrônico, da Prefeitura Municipal de Teresina, em 22 de abril de 2020, é veiculada notícia de que a PSR participa de atividades informativas dentro de abrigo, com foco no auxílio emergencial, perigos da COVID-19 e uso de "entorpecentes", um termo já superado, mas que denota a linguagem proibicionista. Importante a ênfase no auxílio emergencial, sobretudo para a PSR, com dificuldades de acesso a direitos, mas, o foco dos outros temas, destaca a do- 
ença, quando o foco tinha que ser os determinantes sociais do processo saúde doença. Em 07 de maio de 2020 é noticiado pelo site da SEMCASPI, "doações" de 35 máscaras caseiras por uma microempresa, o que desconfigura direitos, anunciados como doação, dádiva, sem a insígnia da cidadania, além de ser associada ao nome de uma empresa, o que pode redundar em marketing publicitário". No dia 26 de maio de 2020, a TV Clube, transmite a reportagem intitulada "Nenhum morador de rua foi diagnosticado com COVID-19 em Teresina", tendo sido constatado 48 com sintomas de gripes, entre março e maio, o que coloca em destaque apenas a realidade vivida no momento por esse segmento, sem que se projete cenários futuros.

Em duas reportagens distintas, foram destacadas a atuação de duas assistentes sociais junto à PSR, uma delas vinculada ao Consultório na Rua (em 25 de junho de 2020), que difundiu informação, como a distribuição de pontos pela cidade com sabão líquido em praças e kits de higiene e informava a necessidade de outro olhar sem preconceito com essa relação a esse segmento, que vem crescendo. A outra assistente social, é vinculada ao território da Superintendência de Desenvolvimento Urbano - SDU Sudeste, que atua na busca ativa desse segmento, cuja abordagem se centra em orientações sobre a prevenção do contagio à COVID-19 e que "durante o atendimento é feita a orientação e preenchimento de um cadastro social", acompanhado de encaminhamento para o Centro de Referência Especializado da Assistência Social - CREAS, haja vista que "casos de pessoas que vivem em situação de rua são considerados atendimentos de alta complexidade", pelo suposto do rompimento do vínculo familiar, confirmando a intersetorialidade entre a política de assistência e saúde.

Além do abrigamento, o foco das ações de profissionais do SUS e SUAS se volta para ações "informativas", para explicar os impactos e as medidas de higiene a serem adotadas para prevenção e promoção da saúde e "lúdicas", o entretenimento. O secretário de Assistência social enfatiza a colaboração de movimentos independentes e religiosos sobretudo para desenvolver atividades recreativas com esse grupo, via voluntariado, que é chamado a se fazer presente. (Site PMT, 22/04), o que enseja ações de capitalização das iniciativas solidárias da sociedade, e risco de desprofissionalização das ações. 


\section{Considerações finais}

O novo contexto, impõe não apenas novas ações, mas requer do Serviço Social, não apenas sistematizar o experienciado, mas, também realizar densas análises, pelas possibilidades de novas requisições, que podem fortalecer a categoria ou contribuir no seu minar, pela desprofissionalização, ou descaracterização de atribuições e competências. Como visto, o assistente social ganha visibilidade midiática no contexto pandêmico, no cenário teresinense, pelas ações de orientação que desenvolve e divulgação de informações, pré-requisito fundamental para o exercício da cidadania, buscando ocupar bem o espaço, ao se referir sobre a PSR para combater preconceito e sugerir novos olhares para um segmento que cresce e cuja realidade ganha maior complexidade. É chamado ainda para realizar "preenchimento de cadastro social", cujo objetivo não é especificado/revelado na matéria podendo ser usado para maior controle do segmento, ou, de outra maneira, para conhecê-la melhor e de forma mais embasada, servir para criar estratégias mais qualificadas de ação.

Mas, como visto, a maioria das respostas e decisões tomadas no contexto pandêmico em solo teresinense, prescindiu da participação social, postulado pela Constituição Federal de 1988 para a formulação de políticas sociais. Há indícios de que conselheiros de saúde ou assistência social sequer foram consultados. O contexto de distanciamento físico, pode justificar ações autoritárias, o que constitui risco para as conquistas democráticas, pois o que se tem visto é que há uma tendência de em nome da segurança (em geral, inclusive de não contrair vírus), as pessoas abram mão de direitos, inclusive civis.

O momento clama por reinvenção dos mecanismos de participação. Representantes da PSR ao serem ouvidos nas reportagens veiculadas, mostram que apesar de tudo, lutam pelo direito de resistir, inclusive a formatos de serviços ofertados que vão de encontro às suas necessidades.

Como esclarece Luciana Ferriani (2020) "o direito de resistência é o direito que todas as pessoas têm de resistir ou de se insurgir contra fatores que ameacem a sobrevivência". O Serviço Social é convocado a apoiar as iniciativas populares, assegurar a qualidade dos 
serviços prestados e reinventar abordagens e práticas. O desafio está posto.

\section{Referências}

ABRASCO. Plano nacional de enfrentamento à pandemia da COVID19. Brasília: ABRASCO, 2020. Versão 03/07/2020. Disponível em: <https://www.abrasco.org.br/site/wp-content/uploads/2020/07/ PEP-COVID-19_COMPLETO_FINAL.pdf>. Acesso em: 22 ago. 2020.

ABREU, M. M. Serviço Social e a organização da cultura: perfis pedagógicos da prática profissional. São Paulo: Cortez, 2002.

AMAPI. Juiz fixa medidas para atendimento a moradores de rua em Teresina durante a pandemia do coronavírus. 2020. Disponível em: <http://www.amapi.org.br/juiz-fixa-medidas-para-atendimento-amoradores-de-rua-em-teresina-durante-a-pandemia-docoronavirus/>. Acesso em: 29 ago. 2020.

BARDIN, L. Análise de conteúdo. Lisboa: Edições 7, 1988.

BOBBIO, N. A era dos direitos. 7. ed. Rio de Janeiro: Elsevier, 2004.

BRASIL. Caderno de Orientações técnicas: Atendimento no SUAS às famílias e aos indivíduos em situação de vulnerabilidade e risco pessoal e social por violação de direitos associada ao consumo de álcool e outras drogas. Brasília: Ministério do Desenvolvimento Social e Combate à Fome, 2016.

CARPASO, C. Pessoas em situação de rua serão acolhidas em escola para quarentena. Cidade Verde, 25 de março de 2020. Disponível em:

$<$ https://cidadeverde.com/coronavirus/104759/pessoas-em-situacao-de-rua-serao-acolhidas-em-escola-para-quarentena>. Acesso em: 24 ago. 2020.

COSTA, L. Teresina ganha centro de acolhimento para casos leves de COVID-19. Governo do estado do Piauí. 2020. Disponível em: <https://www.pi.gov.br/noticias/teresina-ganha-centro-de-acolhimento-para-casos-leves-de-covid-19/>. Acesso em: 24 ago. 2020. 
CONSELHO REGIONAL DE SERVIÇO SOCIAL - Rio de Janeiro - CRESSRJ. Assistente social: ética e direitos: coletânea de leis e resoluções. 4. ed. Rio de Janeiro: CRESSRJ, 2005.

DEFENSORIA consegue liminar com medidas de proteção para a população em situação de rua. Defensoria Pública do estado do Piauí, 26 de março de 2020. Disponível em:

$<$ http://www.defensoria.pi.def.br/defensoria-consegue-liminar-commedidas-de-protecao-para-a-populacao-em-situacao-de-rua/>. Acesso em: 29 ago. 2020.

FAZENDA da Paz irá gerenciar abrigos de isolamento para pessoas com COVID-19. Fazendo da Paz, 20 de maio de 2020. Disponível em: <http://www.fazendadapaz.org.br/fazenda-da-paz-ira-gerenciar-abrigos-de-isolamento-para-pessoas-com-covid-19/>. Acesso em: 23 ago. 2020.

FERRIANI, L. P. Direito de resistência e a desobediência civil. MigaIhas, 21 de agosto 2020. Disponível em: <https://www.migalhas.com.br/depeso/228832/direito-de-resistencia-e-desobediencia-civil>. Acesso em: 22 ago. 2020.

FUNDAÇÃO INSTITUTO OSWALDO CRUZ - FIOCRUZ. Emergência internacional: Como o SUS se prepara para enfrentar epidemias como a do novo coronavírus. RADIS, Rio de Janeiro, n. 2010, março, 2020.

GRAMSCI, A. Concepção dialética da história. Rio de Janeiro: Civilização Brasileira, 1978.

GUIMARÃES, T. A. A.; ROSA, L. C. S. A remanicomialização do cuidado em saúde mental no Brasil no período de 2010 a 2019: análise de uma conjuntura antirreformista. $\mathbf{O}$ social em questão. Rio de Janeiro, ano XXII, n. 44, mai./ago., 2019. Disponível em: <http://osocialemquestao.ser.puc-rio.br/media/OSQ_44_art5.pdf>. Acesso em: 22 ago. 2020.

HENRIQUES, C. M. P. VASCONCELOS, W. Crises dentro da crise: respostas, incertezas e desencontros no combate à pandemia da COVID19 no Brasil. Estudos Avançados, São Paulo, v. 34, n. 99, p. 25-44, mai./ago., 2020. 
IAMAMOTO, M.; CARVALHO, R. Relações sociais e Serviço Social no Brasil: esboço de uma interpretação histórico-metodológica. 9. ed. São Paulo: Cortez, 1993.

. O Serviço Social na contemporaneidade: trabalho e formação profissional. São Paulo: Cortez, 1998.

INSTITUTO BRASILEIRO DE GEOGRAFIA E ESTATÍ́sTICA - IBGE. Censo demográfico 2010. Rio de Janeiro: IBGE, 2011.

JUIZ determina medidas para atender moradores de rua durante quarentena em Teresina. 2020. G1 PI, 26 de março de 2020. Disponível em:

<https://g1.globo.com/pi/piaui/noticia/2020/03/26/juiz-determinamedidas-para-atender-moradores-de-rua-durante-quarentena-emteresina.ghtml>. Acesso em: 29 ago. 2020.

MARTINS, A. Firmino Filho confirma duas mortes por COVID-19 em Teresina. GP1, 29 de março de 2020. Disponível em: <https:// www.gp1.com.br/noticias/firmino-filho-confirma-duas-mortes-porcovid-19-em-teresina-474831.html>. Acesso em: 23 ago. 2020.

MARX, K; ENGELS, F. A ideologia alemã. 6. ed. São Paulo: Martins Fontes, 2001.

MOTA, A. E. Cultura da crise e seguridade social: Um estudo sobre as tendências da previdência e da assistência social brasileira nos anos 80 e 90. São Paulo: Cortez, 1995.

OLIVEIRA, L. C. Moradores de rua se recusam a ficar em abrigo de Teresina. Portal odia, 20 de junho de 2020. Disponível em: <https:// www.portalodia.com/noticias/piaui/moradores-de-rua-se-recusama-ficar-em-abrigo-de-teresina-377656.html>. Acesso em: 29 ago. 2020.

PEREIRA, P. A. P. Necessidades humanas: subsídios à crítica dos mínimos sociais. São Paulo: Cortez, 2000.

PREFEITURA DE TERESINA. FMS tem força tarefa para garantir atendimento em saúde mental durante a pandemia. 2020. Disponível em: <https://pmt.pi.gov.br/2020/05/04/fms-tem-forca-tarefa-para-garan- 
tir-atendimento-em-saude-mental-durante-a-pandemia/>. Acesso em: 24 ago. 2020.

. Mais de $\mathbf{4 0}$ moradores de rua apresentaram sintomas gripais em Teresina. 2020. Disponível em: <https://pmt.pi.gov.br/ 2020/05/26/mais-de-40-moradores-de-rua-apresentaram-sintomasgripais-em-teresina/>. Acesso em: 28 set. 2020.

. Moradores em situação de rua participam de atividades informativas dentro de abrigo. 2020. Disponível em: <https://pmt.pi.gov.br/2020/04/22/moradores-em-situacao-de-rua-participam-deatividades-informativas-dentro-de-abrigo/>. Acesso em: 29 ago. 2020.

. SDU Sudeste realiza atendimento a pessoas em situação de rua durante pandemia. 2020. Disponível em: <https:// pmt.pi.gov.br/2020/06/04/sdu-sudeste-realiza-atendimento-a-pessoas-em-situacao-de-rua-durante-pandemia/>. Acesso em: 29 ago. 2020.

PLANO MUNICIPAL DE ASSISTÊNCIA SOCIAL, 2018- 2021. Teresina: SEMCASPI, 2018. Disponível em: <https://semcaspi.teresina.pi.gov.br/wp-content/uploads/sites/26/2018/11/PLANO-MUNICIPALDE-ASSISTENCIA-SOCIAL-2018-2021.pdf.>. Acesso em: 22 ago. 2020.

SARLET, I. W.; MOLINARO, C. A. Direito à informação e direito de acesso à informação como direitos fundamentais na Constituição brasileira. Revista da AGU, Brasília - DF, Ano XIII, n. 42, p. 09-38, out./ dez. 2014.

SEABRA, C. P. M. R.; ROSA, L. C.S. Atuação do Ministério Público em prol da qualidade da atenção à pessoa com transtorno mental no Piauí. Revista da Corregedoria Nacional: atuação do Ministério Público brasileiro na área de evolução humana e qualidade de vida/Conselho Nacional do Ministério Público, - Vol. VI - Brasília: CNMP, 2018, p. 8295.

SENNETT, R. O declínio do homem público: as tiranias da intimidade. São Paulo: Companhia das Letras, 1988. 
SORJ, B; MARTUCCELLI, D. O desafio latino-americano: coesão social e democracia. Rio de Janeiro: Civilização Brasileira, 2008.

SOUSA, G. Moradores de rua em Teresina resistem em ir a abrigo montado em estádio. Cidade Verde, 08 de maio de 2020. Disponível em: <https://cidadeverde.com/coronavirus/107073/moradores-de-rua-emteresina-resistem-em-ir-a-abrigo-montado-em-estadio>. Acesso em: 29 ago. 2020.

SZASZ, T. Cruel compaixão. Campinas: Papirus, 1994.

TEIXEIRA, E. A realidade de quem não tem como evitar aglomeração: moradores de rua disputam doação de comida. Portal Oitomeia, 25 de março de 2020. Disponível em: <https://www.oitomeia.com.br/noticias/2020/03/25/moradores-derua-na-pandemia-em-teresina-estamos-pior-do-que-coposdescartaveis/>. Acesso em: 24 ago. 2020.

TERESINA. Gabinete do Prefeito. Decreto no 19.537, de 20 de março de 2020. Declara "estado de calamidade pública", em razão do agravamento da crise de saúde pública decorrente da pandemia de doença infecciosa viral respiratória, causada pelo novo coronavírus (COVID-19) e suas repercussões nas finanças públicas municipais, e para os fins do art. 65, da Lei Complementar no 101, de 4 de maio de 2000, e dá outras providências. Disponível em: <https://pmt.pi.gov.br/wpcontent/uploads/sites/34/2020/03/Decreto-n\%C3\%82\%C2\%BA19.537-de-20.03.2020-Declara-estado-de-calamidade-p \%C3\%83\%C2\%BAblica-coronav\%C3\%83_rus-COVID-19.pdf>. Acesso em: 23 ago. 2020.

. Gabinete do Prefeito._Lei no 5.499, de 9 de março de 2020. Dispõe sobre as medidas para enfrentamento da emergência de saúde pública decorrente do coronavírus. Diário Oficial do Município: Ano 2020 - Anexo ao DOM № 2.726 - 12 de março de 2020. Disponível em: <http://dom.pmt.pi.gov.br/admin/upload/ANEXO\%20AO \%20DOM2726-12032020-ASSINADO.pdf>. Acesso em: 23 ago. 2020. 